\title{
Indicadores Educacionais do território do Piemonte da Diamantina-Bahia: apontamentos iniciais
}

\author{
Educational Indicators in the Diamantine-Bahia Piedmont territory: \\ initial notes
}

\author{
Elizeu Clementino de SOUZA ${ }^{1}$ \\ Michael Daian Pacheco RAMOS²
}

\begin{abstract}
Resumo
$\mathrm{O}$ artigo apresenta reflexôes sobre indicadores educacionais do Território do Piemonte da Diamantina na Bahia. Optamos por métodos quantitativos e qualitativos e uma pesquisa documental coletando dados nas bases do INEP. Os resultados apontam uma redução do analfabetismo, contudo as taxas de reprovação e abandono escolar apresentam-se ainda elevadas; há altos índices de distorção idade série, principalmente no ensino fundamental e os municípios apresentaram dificuldades em melhorar os indicadores do Ideb.
\end{abstract}

Palavras-chave: Indicadores Educacionais. Território de Identidade. Estatística da Educação Escolar.
Abstract

The article presents reflections on educational indicators of the Diamantina Piedmont Territory in Bahia. We opted for quantitative and qualitative methods and a documentary research collecting data in INEP bases. The results show a reduction in illiteracy, however, the failure and dropout rates are still high; There are high rates of age distortion, especially in elementary school and the municipalities had difficulties in improving the Ideb indicators.

Keywords: Educational indicators. Identity Territory. School Education Statistics.

1 Bolsista de Produtividade em Pesquisa 1C - CA ED/CNPq. Possui Graduaçáo em Pedagogia pela Universidade Católica do Salvador (1989), Graduação em Pedagogia com Habilitaçáo em Supervisão Escolar pela Universidade Católica do Salvador (1990), Mestrado em Educação pela Universidade Federal da Bahia (1995), Doutorado Sanduíche na Faculdade de Psicologia e Ciências da Educação/Universidade de Lisboa e Doutorado em Educaçáo pela Universidade Federal da Bahia (2004), Pós-Doutorado pela Faculdade de Educação da Universidade de São Paulo (2012), Pós-doutorado/Estágio Sênior na Universidade de Paris 13-França (2018). Editor da Revista Brasileira de Pesquisa (Auto)biográfica (RBPAB), Editor da Revista da FAEEBA-Educação e Contemporaneidade, Membro da Comissáo Editorial da Revista Brasileira de Educaçáo (RBE). Atualmente é Professor Titular da Universidade do Estado da Bahia. E-mail: esclementino@uol.com.br.

2 Possui Licenciatura em Educação Física pela Universidade Estadual de Feira de Santana, UEFS, (2008), especializaçáo em Metodologia e didática do ensino superior, pela Faculdade católica de ciência econômicas da Bahia, FACEBA, (2010) e especialização em Metodologia do ensino da educação física e esporte, pela Universidade do estado da bahia, (2010) e Mestre em Educação pela Universidade Estadual de Feira de Santana (2014). Atualmente é professor do curso de Licenciatura em Educaçáo Física da Universidade do Estado da Bahia, Campus IV - Jacobina-Bahia. E-mail: michaeluneb@gmail.com.

\begin{tabular}{|l|l|l|l|l|l|} 
R. Educ. Públ. & Cuiabá & v. 28 & n. 69 & p. 677-699 & set./dez. 2019 \\
\hline
\end{tabular}




\section{Introdução}

Este artigo apresenta reflexôes sobre alguns indicadores educacionais do Território do Piemonte da Diamantina na Bahia, especialmente, a taxa de analfabetismo de pessoas acima de 15 anos, a distorção idade-série, o rendimento escolar (aprovação, reprovação e abandono) e o Índice de Desenvolvimento da Educação Básica (Ideb), com o intuito de contribuir para a elaboração e acompanhamento das políticas públicas educacionais.

A noção de Território de Identidade tem se configurado como uma política de gestão do Governo do Estado da Bahia, com o objetivo de identificar prioridades temáticas definidas a partir da realidade local, possibilitando o desenvolvimento equilibrado e sustentável entre as regiōes. Essa divisão está amparada através do Decreto 12.354 de 25 de agosto de 2010, ao reconhecer e definir a existência de 27 Territórios de Identidade no Estado da Bahia, constituídos a partir das especificidades de cada mesorregião.

O Território do Piemonte da Diamantina constitui um dos vinte e sete (27) Territórios de Identidade do Estado da Bahia. Neste Território, estão localizados nove (9) municípios: Caém, Jacobina, Miguel Calmon, Mirangaba, Ourolândia, Saúde, Serrolândia, Umburanas e Várzea Nova.

No âmbito educacional brasileiro, consolida-se com a Sinopse da Educação Básica por meio do censo escolar e da implementação do Sistema de Avaliação da Educação Básica, ambos desenvolvidos pelo INEP, a produção de estatísticas e indicadores, implicando na ampliação de forma significativa no contexto atual, permitindo diagnósticos mais fundamentados. Almeida e Wolynec (1998) apontam que a produção de indicadores educacionais comparáveis passou a fazer parte da agenda política do Brasil, a partir de 1995, principalmente após a publicação do World Handbook of Education, pela Unesco, em 1951. Por conseguinte, vários países da América Latina, apresentam evoluçôes na produção de informaçóes e estatísticas sobre a educação. No Brasil, os autores destacam a criaçáo do Sistema Integrado de Informaçóes Educacionais (SIEd) e a reestruturação do Instituto Nacional de Estudos e Pesquisas Educacionais (Inep). Atualmente o Instituto Nacional de Pesquisa Educacional Anísio Teixeira (Inep) é o principal órgáo que produz e socializa indicadores sobre a educação em nosso país.

Compreendemos que os indicadores educacionais buscam atribuir valor estatístico à qualidade do ensino, vinculando-se não apenas ao desempenho dos estudantes bem como ao contexto econômico e social em que ocorre o processo educativo. De acordo com o Inep, eles são úteis principalmente para o monitoramento dos sistemas educacionais, considerando o acesso, a permanência 
e a aprendizagem de todos os alunos (INEP, 2017a). Portanto, esses indicadores auxiliam na criação de políticas públicas voltadas para a melhoria da qualidade da educação.

Ao analisarmos indicadores educacionais do Território do Piemonte da Diamantina na Bahia dialogamos com questóes sistematizadas por Almeida e Wolynec (1998), Souza (2010), Matos e Rodrigues (2016) e Vitelli, Fristsch e Corsetti (2018), tendo em vista modos como os autores se debruçaram sobre produção, análise e comparação dos inúmeros indicadores educacionais brasileiros, possibilitando-nos indicar pistas sobre programas e suas interfaces com a organização das redes de ensino e seus desdobramentos nas escolas.

Almeida e Wolynec (1998) abordam historicamente os esforços internacionais, desenvolvidos pela Unesco e pela Organização para a Cooperação e Desenvolvimento Econômico (OCDE) na produção de indicadores educacionais comparáveis, inserindo a participação do Brasil. Os autores abordaram também as diversas iniciativas brasileiras, juntamente, com outros países da América Latina em produzir indicadores educacionais internacionais, evidenciando o interesse que essa questáo tem despertado no planejamento e definição de políticas educacionais.

Souza (2010) aponta que os indicadores educacionais são usados com três finalidades principais: contribuir para o diagnóstico sobre problemas como repetência e inclusão educacional; fazer comparaçóes nacionais e internacionais que permitem identificar deficiências importantes nos recursos humanos, físicos e financeiros e na gestão educacional, especialmente quando expressadas por desigualdades educacionais; e formular metas, principalmente para sistemas de ensino e escolas, que focalizem o trabalho escolar na obtenção de resultados mais congruentes com desempenhos aceitáveis.

Matos e Rodrigues (2016), analisando a relação entre os indicadores educacionais e o contexto escolar, buscaram relacionar características das escolas e a associação com à probabilidade de atingir a meta do Índice de Desenvolvimento da Educação Básica (Ideb). Utilizando-se de métodos quantitativos, através da estatística descritiva, os autores observaram que nos anos iniciais, a variável de maior impacto sobre a probabilidade de a escola atingir a meta do Ideb é a infraestrutura. Por outro lado, nos anos finais, as variáveis que mais impactam são o nível socioeconômico e a infraestrutura.

Vitelli, Fritsch e Corsetti (2018) destacam que o uso de indicadores como instrumento de gestáo tem relevância tanto no planejamento quanto no monitoramento de práticas desenvolvidas para a melhoria da qualidade de uma ação, de um serviço, de um produto ou de uma política. Porém, com o intuito de avaliar a qualidade da educação, consideram-se insuficientes e limitados. 
Nesse sentido, a reflexão proposta por este estudo sobre os indicadores educacionais do Território do Piemonte da Diamantina, torna-se necessária e situa-se em um cenário contemporâneo, visto que na esfera estadual, há implementação do programa "Educar para transformar: um pacto pela educação", em âmbito municipal há açôes de construção e/ou efetivação dos Planos Municipais de Educação (2014-2024) para os próximos dez anos em adequação ao Plano Nacional de Educaçáo (PNE) (BRASIL, 2014) que implica em desdobramentos diversos no cotidiano das escolas e na organizaçáo das redes de ensino. Por fim, ocorre a implementação da Proposta de Emenda Constitucional 251/2016 (BRASIL, 2016) que coloca um teto para os gastos públicos por 20 anos, impactando diversos setores, dentre eles a educaçáo.

Sendo assim, investigar indicadores educacionais é uma das diferentes possibilidades de acompanhar o cenário educativo no país, acarretando condiçóes mais concretas de propor mudanças, direçóes e focos nos encaminhamentos das políticas públicas.

\section{Metodologia}

Desenvolvemos uma pesquisa documental (BOGDAN; BIKLEN, 1994), na base de dados do Inep, selecionando e coletando alguns indicadores educacionais do Território do Piemonte da Diamantina na Bahia. Dessa forma, articulamos métodos quantitativos e qualitativos que de acordo com Minayo e Sanches (1993) há trabalhos com dados e indicadores no sentindo de torná-los inteligíveis em concomitância com reflexóes aprofundadas sobre a complexidade dos fenômenos identificados, em nosso caso dos indicadores educacionais.

A coleta dos dados teve como centralidade os dados do Censo Escolar da Educação Básica do ano de 2017 (INEP, 2018), a Pesquisa Nacional por Amostra em Domicílio (PNAD, 2015) e o Índice de Desenvolvimento da Educaçáo Básica dos anos de 2005 à 2015. Esse conjunto de dados nos possibilitou reunir e sistematizar informaçôes inéditas sobre indicadores educacionais dos municípios do Território do Piemonte da Diamantina.

O Censo Escolar é o principal instrumento de coleta de informações da educação básica e a mais importante pesquisa estatística educacional brasileira. É coordenado pelo Instituto Nacional de Estudos e Pesquisa Educação Anísio Teixeira (Inep) e realizado em regime de colaboraçáo entre as secretarias estaduais e municipais de educaçáo e com a participação de todas as escolas públicas e privadas do país.

Os dados do Censo Escolar são divulgados no site do Inep (http://inep.gov.

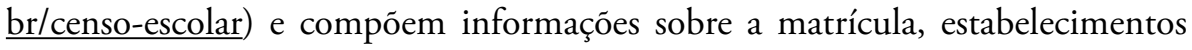


de ensino, docente e turma. É possível selecionar os dados por regiōes, estado, município e escola. Desse modo, selecionamos algumas informaçôes acerca do Território do Piemonte da Diamantina.

A Pesquisa Nacional por Amostra de Domicílio (PNAD) é uma pesquisa realizada pelo Instituto Brasileiro de Geografia e Estatística (IBGE) em uma amostra de domicílios brasileiros que investiga diversas características socioeconômicas da sociedade. A pesquisa é feita em todas as regióes do Brasil. Os indicadores apresentados são disponibilizados em publicaçóes, bem como no site do IBGE.

O Índice de Desenvolvimento da Educação Básica (Ideb) é um indicador de qualidade educacional que combina informaçóes de desempenho em exames padronizados (Prova Brasil ${ }^{3}$ e Saeb) com informaçóes que articulam dados referentes ao fluxo escolar (aprovação, reprovação e abandono) e desempenho dos alunos das series finais de cada fase ou etapa nas avaliaçóes Saeb. Tal indicador foi formulado para medir a qualidade do aprendizado nacional e estabelecer metas para a melhoria do ensino. As médias de desempenho utilizadas são as da Prova Brasil, para escolas, municípios e estado, e do Sistema de Avaliação da Educação Básica (Saeb), para as Unidades Federativas e o País (INEP, 2017a).

Os resultados do Ideb foram coletados através da consulta ao Portal do Inep: http://ideb.inep.gov.br/. Neste site é possível encontrar o Ideb do Brasil, dos estados, dos municípios e das escolas. Os resultados são divulgados de acordo com as séries avaliadas ( $5^{\circ}$ ano e $9^{\circ}$ ano do ensino fundamental e $3^{\circ}$ do ensino médio).

\section{Indicadores Educacionais do Território do Piemonte da Diamantina-Bahia}

\subsection{Sobre as taxas de analfabetismo, distorção idade-série e rendimento}

Os dados relacionados ao analfabetismo, à distorção idade-série e ao rendimento escolar compóem respectivamente os indicadores sociodemográficos e os indicadores de eficiência e rendimento escolar.

Este índice de analfabetismo avalia o percentual de pessoas analfabetas em determinada faixa etária. O IBGE considera a faixa etária de 15 anos ou

3 A partir de 2019 a Avaliação Nacional da Alfabetização (ANA) e a Avaliação Nacional do Rendimento Escolar (Anresc, também conhecida como Prova Brasil) passam a ser identificadas apenas por Saeb. 
mais, os dados são agregados em Brasil, grandes regiōes, unidade da federação e municípios. É considerada analfabeta a pessoa que declara não saber ler e escrever um bilhete simples no idioma que conhece. Aquela que aprendeu a ler e escrever, mas esqueceu, e a que apenas assina o próprio nome é, também, considerada analfabeta (INEP, 2004).

De acordo com dados da PNAD (2015) no Brasil o percentual de pessoas analfabetas acima de 15 anos de idade ou mais, foi estimada em 8,3\% (13,2 milhóes de pessoas). No ano de 2013, esses dados haviam sido 8,5\% (13,3 milhôes de pessoas) apresentando uma ínfima redução em relação aos dados atuais. Quando comparada a outras regiôes do Brasil, a regiáo Nordeste continua sendo a que apresenta os maiores valores percentuais de pessoas analfabetas, com $16,6 \%$ do total do país. Os menores índices, ainda se concentram nas regióes Sul e Sudeste, com respectivamente 4,4\% e 4,6\%. (PNAD, 2015).

No país, a proporção de analfabetos de 15 anos ou mais, tem quantitativos próximos em relação ao gênero, ou seja, homens $49,8 \%$ e mulheres $50,2 \%$. Contudo, compreendemos que o analfabetismo atinge de forma diferenciada os vários setores da população. Quando observamos a variável de idade, por exemplo, percebemos que $23,1 \%$ da população brasileira com mais de 60 anos não tem nenhuma instruçáo ou possui menos de um ano de escolarização (PNAD, 2015).

A manutenção da quantidade de analfabetos no país pode ser explicada a partir dos argumentos de Souza (1999), quando afirma que:

A constância desse volume, em parte, pode ser explicada pela manutençáo dos analfabetos de geraçóes passadas na populaçáo. Quando o ensino, especialmente o escolar, focaliza quase que exclusivamente a população jovem, tornase, após certa idade, difícil aos adultos reverter sua condição de analfabeto. Assim, o envelhecimento de uma geraçấo de analfabetos pode, nesse caso, ser considerado o componente demográfico da manutenção do analfabetismo. Entretanto, para ser mantido no tempo, o estoque de analfabetos exige reposição, ou seja, o surgimento de novos analfabetos nas geraçôes mais novas. Logo, além dos aspectos essencialmente relacionados à dinâmica demográfica, o analfabetismo está também relacionado a condiçōes que "produzem" novos analfabetos (SOUZA, 1999, p. 172).

$\mathrm{Na}$ Bahia, o analfabetismo em 2013, considerando a população com mais de 15 anos de idade era de 14,9\% (PNAD, 2015). Essa é uma taxa que se apresenta elevada quando comparada aos valores percentuais do país que é de $8,3 \%$. No 
entanto, os dados da Síntese dos Indicadores Sociais (IBGE, 2013) evidenciam que para a populaçáo com mais de 15 anos de idade do estado da Bahia, houve uma redução do analfabetismo de 2007 a 2013 de 4,6 p.p, pois em 2007 era de $18,3 \%$.

Estes dados são fundamentais para entendermos como os avanços na área educacional se dão de forma heterogênea e evidencia o perfil dos sujeitos que não são alcançados e plenamente atendidos pelas políticas públicas de educação. O Gráfico 1 apresenta a distribuição em relação ao analfabetismo da população acima de 15 anos dos municípios do Território do Piemonte da Diamantina.

\section{Gráfico 1 - Distribuição da taxa de analfabetismo da população acima de 15 anos do Território do Piemonte da Diamantina-Bahia}

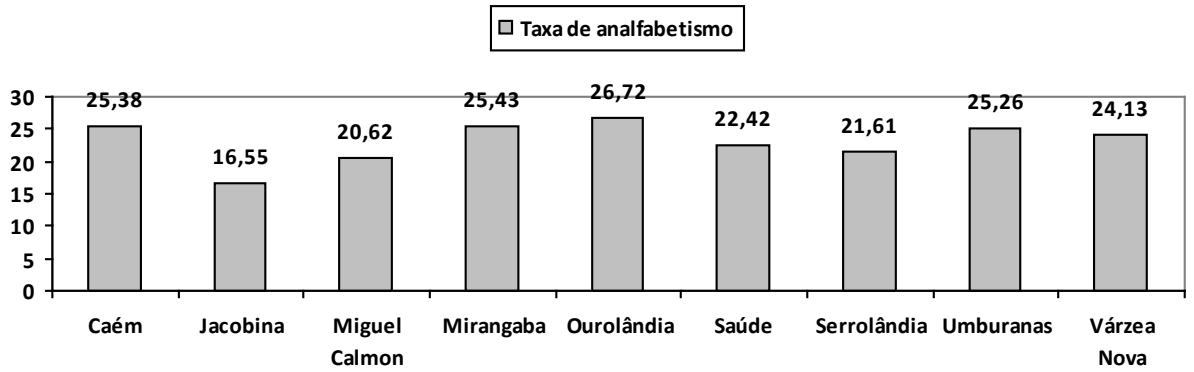

Fonte: Elaborada pelos autores a partir dos dados do IBGE (2013).

Na leitura do gráfico identificamos que com exceção do município de Jacobina que possui $16,55 \%$, todos os outros municípios possuem mais de $20 \%$ de sua população acima de 15 anos analfabeta. $\mathrm{O}$ município de Ourolândia possui o maior percentual no território estudado, correspondendo a $26,72 \%$, seguido de Mirangaba (25,43\%), Caém (25,38\%), Umburanas (25,26\%), Várzea Nova (24,13\%), Saúde (22,42\%), Serrolândia (21,61\%) e Miguel Calmon (20,62\%).

No sentido de subsidiar a implantaçáo das políticas para a erradicação do analfabetismo o Ministério da Educação publicou um estudo denominado Mapa do Analfabetismo no Brasil (INEP, 2003). Nossos dados ratificam o que aponta o estudo.

Em termos relativos, as maiores taxas de analfabetismo estão em municípios localizados nas Regiōes Norte e Nordeste. Esse quadro é preocupante, em função das baixas condiçóes socioeconômicas dessas localidades, que, diante de suas características, promovem a manutenção dessa situação de exclusão social (INEP, 2003). 
Portanto, percebemos que na maioria dos municípios investigados os valores percentuais da populaçáo acima de 15 anos analfabeta estáo superiores do que a média estadual $(18,3 \%)$ e nacional $(8,5 \%)$. A discrepância dos percentuais de analfabetos do Brasil, das grandes regióes, na Bahia e no âmbito do Território do Piemonte da Diamantina reafirmam as desigualdades sociais e regionais, marca histórica e característica do país.

De acordo com o referido documento do Inep (2003) os motivos para o fracasso brasileiro na alfabetização de seus jovens são variados, que vai desde a escola de baixa qualidade (em especial nas regiôes mais pobres do País e nos bairros mais pobres das grandes cidades) passando pelo trabalho precoce dos estudantes, da baixa escolarização dos pais, até o despreparo da rede de ensino para lidar com essa população.

Dessa forma, apontamos a urgência e atenção na construção de políticas públicas educacionais que visem a superação do analfabetismo, não basta a queda da taxa, mas a diminuição dos números absolutos.

A erradicação do analfabetismo tem se configurado como uma preocupação das políticas públicas educacionais, configurando-se como uma das dez (10) diretrizes do PNE (BRASIL, 2014). O objetivo no combate ao analfabetismo esteve presente em outros Planos Nacionais de Educação e vêm caminhando a passos lentos, com redução ínfima nos dados absolutos. Atualmente, o PNE aponta em suas metas 8 e 9 uma preocupação direta na erradicação do analfabetismo em nosso país (BRASIL, 2014).

Os planos municipais de educação do Território do Piemonte da Diamantina também apontam preocupação em combater e superar o analfabetismo nos municípios, seguindo o que apontam as metas do plano nacional e estadual de educação.

Pinto e colaboradores (2000) afirmam que a solução para o analfabetismo é assegurar escola para todos na idade adequada, porém se esta escola não for de qualidade, continuaremos produzindo o analfabeto funcional, que deterá anos de estudo, mas não consegue avançar além das séries iniciais.

Entendemos que a luta para a superação do analfabetismo não deve centrar-se apenas na educaçáo, sobretudo devemos articular com políticas de distribuição de renda. Pinto e colaboradores (2000) especificam essa articulação, afirmando que:

Distribuição de renda e de educação são duas ações que caminham juntas. Políticas estruturais de distribuição de renda (como a reforma agrária) assim como as emergenciais (como os programas de renda mínima) aumentam as chances de permanência das crianças e 
jovens nas escolas. Por sua vez, crianças e jovens com maior escolaridade passam a ocupar empregos mais bem remunerados. Os ganhos sociais advindos de ações dessa natureza, com certeza, trarão impactos muito positivos na sociedade brasileira (PINTO, et. al., 2000, p. 522).

Souza (1999) discute algumas relaçôes entre dinâmica demográfica e o nível educacional da populaçáo a partir do indicador taxa de analfabetismo, demonstrando que a evolução dos índices totais de analfabetismo no tempo depende tanto da estrutura etária da população quanto da capacidade do sistema de ensino de alfabetizar indivíduos em todas as idades. Com base nisso, o autor estabelece projeçóes de percentuais futuros de analfabetismo até 2020 concluindo que a velocidade atual de crescimento da alfabetização total é pequena e que seu aumento depende de medidas relacionas à educação de jovens e adultos.

Tudo indica que a dinâmica demográfica agirá no sentido de reduzir as taxas de analfabetismo. A questáo que se coloca é para quanto e quando. Como há reposição do estoque de analfabetos na população, é de se esperar que apenas a dinâmica demográfica seja insuficiente para promover a redução a níveis razoáveis nos próximos anos. Por isso, para acelerar a redução do analfabetismo, é necessário agir ativamente, tanto sobre o estoque existente, quanto sobre as futuras geraçóes. Como a reposiçáo se dá pelas geraçôes mais novas, quanto mais demorar essa ação, por mais tempo perdurará o analfabetismo, mantidas as taxas de superação constantes (SOUZA, 1999, p. 176).

Dito isso, políticas públicas que tenham como foco a erradicação do analfabetismo deverão levar em conta a valorização dos docentes, inclusive com formação e remuneração complementar. Além disso, o país necessita melhorar as condiçóes de trabalho dos profissionais da educação: melhorando a infraestrutura, implementando políticas de formação docente que dialoguem com o cotidiano das escolas e das condiçóes de trabalho dos professores, bem como de políticas de valorização que possam superar a precarização do trabalho e ampliando a jornada escolar dos estudantes.

Outro conjunto de dados que expressam o patamar de desigualdade educacional no Brasil é a distorção idade-série. Em um sistema educacional seriado, existe uma adequaçáo teórica entre a série/ano e a idade do aluno. 
No caso brasileiro, considera-se a idade de 6 anos como a idade adequada para ingresso no ensino fundamental, cuja duração é de 9 anos. Seguindo este raciocínio é possível identificar a idade adequada para cada série, mesmo que com controvérsias sobre tal definição, tendo em vista que se desconsidera os tempos e ritmos de aprendizagens dos alunos e concentra-se a organização na idade. Nesse sentido, a distorção idade-série é um indicador que permite avaliar o percentual de alunos, em cada série, com idade superior a 2 anos da idade recomendada. (INEP, 2017c).

Fernandes e Natezon (2003) observam no caso brasileiro uma melhora neste indicador ao longo do tempo. Todavia, infelizmente, isto ainda é um problema recorrente na realidade educacional brasileira, por exemplo no Estado da Bahia, em 2017, o percentual de distorção idade-série para o ensino fundamental era de $29,9 \%$, já para o ensino médio essa taxa foi 43,6\%. Quando analisamos as diferenças desses valores no fundamental em relação a localidade, identificamos que no contexto urbano o valor é de $28,9 \%$ e no contexto rural é de $32,7 \%$ (INEP, 2017c).

Mapeamos os percentuais de distorção idade-série nos municípios que constituem o Território do Piemonte da Diamantina, conforme a tabela abaixo.

Tabela 1 - Distribuição da taxa de distorção idade-série no ensino fundamental do Território do Piemonte da Diamantina-Bahia

\begin{tabular}{l|c|c|c}
\hline Município & Total & Urbano & Rural \\
\hline Caém & $32,7 \%$ & $26,4 \%$ & $37 \%$ \\
\hline Jacobina & $25,3 \%$ & $24,4 \%$ & $28 \%$ \\
\hline Miguel Calmon & $30,4 \%$ & $29,3 \%$ & $32,2 \%$ \\
\hline Mirangaba & $35,2 \%$ & $44,7 \%$ & $29,7 \%$ \\
\hline Ourolândia & $30,7 \%$ & $34,4 \%$ & $27,1 \%$ \\
\hline Saúde & $36,5 \%$ & $36,2 \%$ & $37,4 \%$ \\
\hline Serrolândia & $18,2 \%$ & $19,5 \%$ & $13,5 \%$ \\
\hline Umburanas & $23,8 \%$ & $25,5 \%$ & $21,8 \%$ \\
\hline Várzea nova & $30 \%$ & $28,9 \%$ & $34,4 \%$ \\
\hline
\end{tabular}

Fonte: Elaborada pelos autores a partir dos dados do INEP (2017c). 
$\mathrm{Na}$ leitura da tabela destacamos que a maioria dos municípios (Caém, Miguel Calmon, Mirangaba, Ourolândia, Saúde e Várzea Nova) que fazem parte do território estudado possuem cerca de um terço de seus estudantes do ensino fundamental com a idade inadequada para a série que estão cursando no ensino fundamental. Entre os municípios investigados, Serrolândia é aquele com a menor taxa de distorção idade-série, com $18,2 \%$, já o município de Saúde apresentou o maior percentual com 36,2\%.

Quando olhamos para a disposição dos valores de distorção idadesérie a partir da localização nos municípios de Caém, Jacobina, Miguel Calmon, Saúde e Várzea Nova as taxas do contexto rural são maiores que no urbano. Contudo, nos municípios de Mirangaba, Ourolândia, Serrolândia e Umburanas os percentuais do meio urbano são maiores que no rural.

Importante demarcar que o problema da distorção idade-série não é apenas entrada do estudante no sistema educacional, pois de acordo com o PNAD (2015) 97\% das crianças de 6 anos estavam frequentando a escola. Algo central nessa trajetória de fracasso escolar é que ao passar dos anos, muitas delas vão ficando para trás. Isto torna-se evidente quando observamos as taxas de distorção idade-série e percebemos que quanto maior a etapa da educação básica, maior o percentual de distorção idade-série. Por exemplo, as taxas do ensino médio (44\%) são maiores do que os anos finais (40\%) e do que os anos iniciais do ensino fundamental (20\%) (INEP, 2017c).

Importante notar que existem três pontos críticos nessa trajetória de fracasso escolar, que é justamente os momentos de transição, a saber: o $3^{\circ}$ ano e o $6^{\circ}$ ano do ensino fundamental e o $1^{\circ}$ ano do ensino médio. Esses pontos equivalem-se ao final do ciclo de alfabetizaçáo, a mudança da sala de aula unidocente para a multidocente e a transferência da gestáo municipal para a estadual.

As consequências do atraso escolar entre crianças e adolescentes deixamnas envolvidas em um ciclo de fracasso escolar.

Esse fenômeno atinge, principalmente, quem vem das camadas mais vulneráveis da população e corre sério risco de exclusão, estando mais propenso a abandonar a escola para ingressar no mercado de trabalho de modo prematuro e precário, sem concluir os estudos. Sáo crianças e adolescentes já privados de outros direitos constitucionais, que não têm assegurados os direitos de aprender e de se desenvolver na idade apropriada (UNICEF, 2018, p. 3). 
Portella, Bussmann e Oliveira (2017) nos alerta sobre a possibilidade que um elevado grau de distorção idade-série pode afetar na acumulação de capital humano por parte da população, carregando não apenas consequências para os indivíduos, como também para a sociedade de maneira geral, afetando o crescimento econômico de longo prazo e a redução na desigualdade social.

Importante notar que às características gerais das crianças e da família possuem relaçáo com a distorção idade-série, conforme nos revela Machado e Gonzaga (2007) onde explica que o público infantil mais vulnerável à ocorrência de defasagem idade-série é formado por: meninos, negros e amarelos, moradores das regiôes onde há maiores dificuldades de oferta educacional, como o Nordeste, pertencentes às famílias maiores, com pais que têm menor nível de instrução e com menor renda familiar per capita.

Portanto, independente dessas variaçóes, esses dados nos apresenta um contexto educacional preocupante, haja vista que uma parte significativa dos estudantes dos municípios investigados apresentam uma distorção entre a idade e a série adequada. Sendo assim, esses municípios, juntamente com o governo do estado da Bahia e a União necessitam construir políticas educacionais focalizadas em melhorar esse cenário.

As taxas de rendimento escolar são compostas e expressam o percentual de alunos aprovados, reprovados e afastados por abandono, elas compóem os indicadores educacionais de eficiência e rendimento (INEP, 2004). Dessa maneira, os índices de aprovação indicam a porcentagem de alunos que, ao final do ano letivo, concluíram satisfatoriamente o ano na qual se encontravam. A de reprovação indica o percentual de estudantes que, ao término do ano letivo, não alcançaram a conclusão satisfatória do ano em que cursava. Por fim, os índices de abandono apontam a quantidade de alunos que deixaram de frequentar a escola após a data de referência do Censo Escolar.

Dados relacionados com a reprovaçáo indicam que na rede estadual da Bahia o maior percentual é no $6^{\circ}$ do ensino fundamental onde $30,3 \%$ dos estudantes são reprovados. Já os maiores percentuais de abandono na rede estadual estão no $4^{\mathrm{o}}$ ano do Ensino Fundamental com 6,2\% dos estudantes abandonando a escola. Os menores índices de aprovação na rede estadual da Bahia se encontram no $1^{\circ}$ ano do ensino médio, com apenas $67,3 \%$ dos estudantes aprovado para o ano seguinte (INEP, 2016).

Em relação ao território estudado a tabela abaixo apresenta a distribuição do indicador de rendimento escolar. 
Tabela 2 - Distribuição da taxa de rendimento (aprovação, reprovação e abandono) no ensino fundamental e médio do Território do Piemonte da Diamantina-Bahia

\begin{tabular}{c|c|c|c|c|c|c}
\hline \multirow{2}{*}{ Município } & \multicolumn{2}{|c|}{ Aprovação } & \multicolumn{2}{c|}{ Reprovação } & \multicolumn{2}{c}{ Abandono } \\
\cline { 2 - 7 } & $\begin{array}{c}\text { Ensino } \\
\text { Fundamental }\end{array}$ & $\begin{array}{c}\text { Ensino } \\
\text { Médio }\end{array}$ & $\begin{array}{c}\text { Ensino } \\
\text { Fundamental }\end{array}$ & $\begin{array}{c}\text { Ensino } \\
\text { Médio }\end{array}$ & $\begin{array}{c}\text { Ensino } \\
\text { Fundamental }\end{array}$ & $\begin{array}{c}\text { Ensino } \\
\text { Médio }\end{array}$ \\
\hline Jacobina & $79,2 \%$ & $72,1 \%$ & $13,9 \%$ & $15,9 \%$ & $6,9 \%$ & $12 \%$ \\
\hline Miguel Calmon & $81,7 \%$ & $80,7 \%$ & $12,9 \%$ & $18,9 \%$ & $5,4 \%$ & $0,4 \%$ \\
\hline Mirangaba & $75,7 \%$ & $77,8 \%$ & $12,7 \%$ & $12,5 \%$ & $11,6 \%$ & $9,7 \%$ \\
\hline Ourolândia & $79,7 \%$ & $62,2 \%$ & $15 \%$ & $32,3 \%$ & $5,3 \%$ & $5,5 \%$ \\
\hline Saúde & $72,5 \%$ & $67,2 \%$ & $20 \%$ & $23,4 \%$ & $7,5 \%$ & $9,4 \%$ \\
\hline Serrolândia & $79,7 \%$ & $81 \%$ & $12,1 \%$ & $12,6 \%$ & $8,2 \%$ & $6,4 \%$ \\
\hline Umburanas & $82 \%$ & $73,5 \%$ & $14 \%$ & $18,9 \%$ & $4,0 \%$ & $6,4 \%$ \\
\hline Várzea nova & $78,1 \%$ & $80,5 \%$ & $15,4 \%$ & $9,4 \%$ & $6,5 \%$ & $10,1 \%$ \\
\hline
\end{tabular}

Fonte: Elaborada pelos autores a partir dos dados do INEP (2016).

É notável que a aprovação no ensino médio é menor do que no ensino fundamental, isto foi recorrente em todos os municípios do território. Em relaçáo ao percentual de reprovação, apenas nos municípios de Mirangaba e Várzea Nova a proporção de estudantes do ensino fundamental reprovados é maior do que no ensino médio. E no que tange a taxa de abandono os municípios de Miguel Calmon, Mirangaba e Serrolândia apresentam percentuais maiores no ensino fundamental do que no médio.

Em relação a aprovação, no ensino fundamental, Jacobina com 83,3\% apresentou o maior valor, já Saúde com $72,5 \%$ o menor. No que se refere ao ensino médio, Serrolândia apresentou o maior percentual com $81 \%$ e Ourolândia o menor com $62,2 \%$.

No que diz respeito a reprovação no ensino fundamental a cidade de Saúde apontou a maior proporção de estudantes, correspondendo a $20 \%$, em contrapartida Jacobina com $12 \%$ a menor taxa. No ensino médio, o município de Ourolândia apontou o maior percentual com 32,3\% de estudantes reprovados e Várzea Nova o menor com 9,4\%. 
Por fim, no que tange ao abandono, no ensino fundamental, Mirangaba apresenta a maior proporção com $11,6 \%$ e Serrolândia a menor com 4,0\%. No que se refere ao ensino médio, Caém sinaliza a maior proporção com $12 \%$ e Miguel Calmon a menor com $0,4 \%$.

Desta forma, vimos que o cenário em relação aos indicadores de rendimento (aprovação, reprovação e abandono) no Território do Piemonte da Diamantina é bem diverso, pois um mesmo município apresenta índices elevados em um critério e péssimas proporções em outros. Algo que nos chama atenção também é que, de maneira geral, esses dados apresentam um cenário educativo que merece bastante atenção por parte dos gestores públicos, principalmente quando focamos nos dados de reprovação e abandono escolar.

Ao teorizarem sobre essa questão Klein e Fontanive (2009), afirmam que:

Uma política de universalização da conclusão da educação básica precisa criar mecanismos para diminuir as taxas de repetência e evasão e aumentar as de conclusão ao longo de um período de tempo. Nesse sentido, devem ser definidas metas realistas baseadas em indicadores mensuráveis, que possam ser acompanhados para aferir a eficácia da política e eventual correção de rumos. (KLEIN; FONTANIVE, 2009, p. 26).

Soares et. al. (2015) desenvolveram uma pesquisa para compreender os fatores associados ao abandono escolar no ensino médio público em Minas Gerais e nos alerta que os principais elementos são: a dificuldade nas disciplinas, ânsia por uma escola diferente, percepção de melhores oportunidades de trabalho com a continuidade dos estudos e a importância atribuída na escolha à escola.

Outros elementos também podem estar associados ao abandono escolar no Brasil, contudo devemos entender esse fenômeno dentro de sua complexidade e Filho e Araújo (2017) nos ajuda a ampliar esta reflexão apresentando que a evasão pode ser considerada um ato solitário e pode denotar o próprio fracasso das relaçóes sociais; não tem uma origem definida e por isso não terá um fim por si só. Desta forma, os autores apontam que drogas, sucessivas reprovaçóes, prostituiçáo, falta de incentivo da família e da escola sáo alguns dos fatores que podem levar o educando a sair da escola.

Portanto, definir políticas públicas de educação e construir ações que contribuam para romper a lógica da reprovação e de abandono são fundamentais, tendo em vista a garantia de princípios centrados numa educação pública, gratuita e universal, como direitos universais. 


\subsection{Sobre o Índice de Desenvolvimento da Educação Básica-Ideb}

Compreendemos que o Ideb é um indicador que tem o potencial de auxiliar na sistematização da qualidade da educação, sobretudo porque possui a capacidade de tornar mais visíveis as fragilidades das políticas educacionais.

O Ideb ${ }^{4}$ analisa a qualidade do ensino e desenvolvimento da aprendizagem dos estudantes, foi criado pelo Inep em 2007 e agrega em um só indicador dois conceitos igualmente importantes para a qualidade da educaçáo: fluxo escolar e médias de desempenho dos estudantes, das escolas e redes de ensino nas avaliaçóes. O indicador é calculado a partir dos dados sobre fluxo escolar, obtidos no Censo Escolar e médias de desempenho nas avaliaçóes do Inep, o Sistema de avaliação da Educação Básica (Saeb) para as unidades da federação e para o país, e a Prova Brasil para os municípios. (INEP, 2017a).

Tabela 3 - Distribuição do Ideb do $5^{\circ}$ e $9^{\circ}$ ano do ensino fundamental e do $3^{\circ}$ ano do ensino da rede estadual da Bahia entre os anos de 2007 à 2015

\begin{tabular}{c|c|c|c}
\hline & $5^{\circ}$ ANO (ef) & $9^{\circ}$ ANO (ef) & $3^{\circ}$ ANO (em) \\
\hline 2007 & 2,6 & 2,7 & 2,8 \\
\hline 2009 & 3,2 & 2,8 & 3,1 \\
\hline 2011 & 3,8 & 2,9 & 3,0 \\
\hline 2013 & 4,0 & 3,1 & 2,8 \\
\hline 2015 & 4,3 & 3,2 & 2,9 \\
\hline
\end{tabular}

Fonte: Elaborada pelos autores (INEP, 2017b).

* Os resultados em cinza referem-se ao IDEB que atingiu a meta daquele ano.

A tabela acima apresenta os dados referentes ao estado da Bahia. Para todas as redes de ensino no estado da Bahia, no $5^{\circ}$ ano do ensino fundamental, o Ideb ampliou de 2,6 em 2007 para 4,3 em 2015, alcançando todas as metas entre os anos de 2009 a 2015 nesta etapa da educação básica. A meta para 2019 é 4,6 (INEP, 2017b).

Em relação ao $9^{\circ}$ ano do ensino fundamental, o Ideb foi de 2,7 em 2007 para 3,2 em 2015. Vejamos que a rede estadual da Bahia só alcançou as metas do Ideb

4 O Índice de Desenvolvimento da Educação Básica foi introduzido na política educacional pelo Plano de Metas Compromisso Todos pela Educação. (BRASIL, 2007). 
de 2007 e 2009, portanto, nas últimas três avaliações o estado não conseguiu atingir suas metas. A meta para 2019 é 4,4 (INEP, 2017b).

Por fim, no ensino médio, o Ideb oscilou de 2,8 em 2007 para 2,9 em 2015. Faz-se necessário salientar que no ano de 2013 e 2015 a rede estadual da Bahia não alcançou as metas projetadas no Ideb para o ensino médio. A meta para 2019 é 4,3 (INEP, 2017b).

Os dados apontam para um cenário que merece uma atenção especial para as políticas educacionais do estado, tendo em vista que os resultados do $9^{\circ}$ ano do ensino fundamental e do $3^{\circ}$ ano do ensino médio apresentam um contexto que exigirá esforços, na tentativa de melhorias da qualidade do ensino.

Especificamente no Território do Piemonte da Diamantina, a tabela 6 apresenta a distribuição dos resultados do Ideb entre os anos de 2005 à 2015.

TABELA 4 - Distribuição do Ideb do $5^{\circ}$ ano do ensino fundamental do Território do Piemonte da Diamantina-Bahia

\begin{tabular}{l|c|c|c|c|c|c|c}
\hline & $\begin{array}{l}\text { IDEB } \\
2005\end{array}$ & $\begin{array}{l}\text { IDEB } \\
2007\end{array}$ & $\begin{array}{c}\text { IDEB } \\
2009\end{array}$ & $\begin{array}{c}\text { IDEB } \\
2011\end{array}$ & $\begin{array}{c}\text { IDEB } \\
2013\end{array}$ & $\begin{array}{c}\text { IDEB } \\
2015\end{array}$ & $\begin{array}{c}\text { META } \\
\text { IDEB 2019 }\end{array}$ \\
\hline Caém & 2,6 & 2,7 & 3,7 & 3,9 & 3,7 & 4,1 & 4,6 \\
\hline $\begin{array}{l}\text { Macobina } \\
\text { Calmon }\end{array}$ & 2,8 & 3,6 & 3,6 & 3,9 & 3,9 & 4,4 & 4,5 \\
\hline Mirangaba & 2,2 & 2,9 & 2,7 & 4,0 & 4,2 & 4,4 & 4,2 \\
\hline Ourolândia & 2,7 & 2,9 & 3,6 & 3,6 & 3,5 & 4,1 & 4,3 \\
\hline Saúde & 2,0 & 2,6 & 2,6 & 3,4 & 3,2 & 3,4 & 4,3 \\
\hline Serrolândia & 2,1 & - & 3,1 & 4,2 & 3,8 & 4,5 & 3,8 \\
\hline Umburanas & 2,6 & 2,7 & 3,7 & 4,4 & 4,0 & 4,2 & 4,3 \\
\hline Várzea Nova & 2,4 & 3,6 & 3,7 & 4,0 & 4,1 & 4,2 & 4,5 \\
\hline
\end{tabular}

Fonte: Elaborada pelos autores (INEP, 2017b).

* Os resultados em cinza referem-se ao IDEB que atingiu a meta daquele ano.

A tabela acima nos permite compreender que desde a implementação do Ideb no ano de 2005, apenas os municípios de Jacobina, Umburanas e Várzea Nova conseguiram alcançar suas metas em todos os anos avaliados. Destacamos 
também que o município de Serrolândia não obteve o indicador no ano de $2007^{5}$, contudo entre os demais anos avaliados conseguiu alcançar as metas previstas.

Um sinal de atenção maior deve ser ligado nos municípios de Caém, Miguel Calmon e Saúde, pois nos últimos 2 anos não conseguiram alcançar as metas previstas. Este dado evidencia um olhar mais atento na definição da política educacional destes municípios, pois como revelam os dados da tabela 6 , existe um indicativo de declínio dos índices do Ideb.

Tais análises reforçam as discussões apresentadas por Alves e Soares (2013), quando afirmam sobre a necessidade de ampliação de estudos sobre os indicadores educacionais, nesse caso o Ideb, possibilitando considerar outras condiçóes estruturantes para aferir a qualidade da educação básica do nosso país.

O estudo desenvolvido por Alves e Soares (2013), parte do valor do Ideb no ano de 2009, ao tomarem as variáveis: a) nível socioeconômico da escola; b) proporção de alunos discriminados por raça e por gênero; c) infraestrutura da escola e d) tamanho e complexidade da escola. Em síntese, os autores apontam que o Ideb das escolas tem uma relação direta com o perfil dos alunos (nesse caso, escola com mais alunos negros tem a probabilidade em ter o Ideb menor), infraestrutura (nesse caso, quanto mais precária a infraestrutura mais baixo será o Ideb) e o tamanho e complexidade (ou seja, quanto maior a escola e mais complexa há uma probabilidade de ter um Ideb mais baixo).

Ainda sobre a discrepância entre o resultado do Ideb e a qualidade da educação oferecida, Alves e Soares (2013) afirmam que:

Um sistema educacional só pode ser dito de qualidade se suas desigualdades sáo também consideradas na análise de seu desempenho. Os resultados descritos na seção anterior evidenciaram que a síntese da qualidade da escola em um único número não contempla as condiçóes desiguais entre os estabelecimentos de ensino. (ALVES; SOARES, 2013, p. 190).

Ao analisarmos os indicadores educacionais no contexto do Estado da Bahia e do Território do Piemonte da Diamantina-Bahia, buscamos aproximaçóes com os estudos de Cabral Neto, Souza e Queiroz (2013), quando avaliam a situação do Ideb do Estado do Rio Grande do Norte, ao afirmarem que:

Esses indicadores educacionais evidenciam a fragilidade do ensino público [...] e, também, são ilustrativos da

5 Número de participantes no SAEB insuficiente para que os resultados sejam divulgados. 
incapacidade do governo de adotar políticas capazes de alterar o quadro caótico da educaçáo, principalmente, mas não exclusivamente, no que concerne à qualidade de ensino. (CABRAL NETO; SOUZA; QUEIROZ, 2013, p. 28).

Ao dialogarmos com Cabral Neto, Souza e Queiroz (2013), percebemos que existem vizinhanças e aproximações na comparação dos dados educacionais, o que provavelmente representa um descaso histórico que foi implementado pelos governos nos processos educacionais dos estados da região nordeste do Brasil.

Ampliando a compreensão de que o alcance das metas do Ideb não depende somente do trabalho desenvolvido na escola, mas está articulando também a outros fatores como por exemplo, a condição socioeconômica dos estudantes, Duarte (2013) desenvolveu um estudo apontando que a presença de alunos em situação de pobreza tem efeito negativo bastante considerável no Ideb da escola, somado a isso adverte ainda que o custo-aluno, população e região também interferem nessa relação. Desta maneira, a escola "[...] tem oferecido percursos diferenciados aos diversos grupos que a frequentam, em especial, a partir da renda e classe social” (DUARTE, 2013, p. 345).

Reafirmamos, a partir do debate posto sobre o Ideb, que a instituição escolar precisa voltar-se para sua função social central que é o aprendizado dos alunos, mas também o reconhecimento de seus múltiplos aspectos e das condiçóes contextuais em que as escolas estão inseridas, garantindo também melhores condiçóes de trabalho para os docentes.

Dito isso, compreendemos que o alcance de metas estipuladas no Ideb das escolas não pode ser compreendida dentro de um viés meritocrático da comunidade escolar, no entanto o que deve ser pautado é a ampliação de mais recursos para a educação e o desenvolvimento de políticas públicas para a população com o intuito de diminuir as desigualdades sociais.

Essa lógica permite compreender o Ideb enquanto um indicador de vulnerabilidade social, apoiando e enfrentando os fundamentos de responsabilização individual do fracasso escolar (FREITAS, 2007). Duarte (2013) alerta para o fato de que

$\mathrm{O}$ uso do Ideb como indicador da necessidade de maiores e novos aportes da política educacional pode vir a romper a lógica convencional da responsabilização (accountability) dos atores pelo mau resultado da atuaçáo da política educacional. Essa nova perspectiva é acionada especialmente quando se visa aportar apoio maior justamente às escolas e aos sistemas educacionais que apresentaram os piores índices (2013, p. 346). 
Portanto, ao apontar alguns indicadores educacionais do Estado da Bahia e do Território do Piemonte temos o entendimento de que os dados evidenciam aspectos relacionados ao cenário educacional, que nos últimos anos vêm melhorando, porém há uma urgência e necessidade de que os avanços se deem de forma mais eficaz. Dessa forma, entendemos que caso não enfrentemos de maneira séria e com qualidade a realidade da educação pública de nosso país terá cada vez mais a precarização das condiçóes do trabalho docente, a permanência das desigualdades educacionais e a letargia na melhoria da qualidade educacional.

\section{Alguns Apontamentos Conclusivos}

O presente trabalho buscou analisar alguns indicadores educacionais do Estado da Bahia, em especial dos municípios do território do Piemonte da Diamantina. Este esforço torna-se relevante, pois até o momento náo identificamos trabalhos de pesquisa que abordassem a temática em questão, numa perspectiva quantitativa e qualitativa.

Consideramos que a busca de uma educação equitativa e de qualidade se articule com a necessidade de identificar, constantemente, indicadores educacionais com mais detalhes e que levem em conta as especificidades do contexto educacional face a progressão, ou não, da implementação e efeitos das políticas públicas educacionais. Nesse sentido, alguns indicadores educacionais que estáo postos neste estudo, podem servir para a construçáo de políticas públicas educacionais no território do Piemonte da Diamantina.

Em síntese, destacamos que os dados do Estado da Bahia e dos municípios do território do Piemonte da Diamantina apresentam ainda índices elevados e preocupantes, no que diz respeito ao analfabetismo, à distorção idade-série, à reprovação e abandono e ao Ideb necessitando de açóes mais efetivas por parte dos governos nas esferas municipais, estadual e federal, com políticas públicas que possibilitem a reversão de um padrão histórico que persiste em converter as desigualdades sociais em desigualdades educacionais.

Assim, compreendemos que esta análise torna-se relevante, pois se por um lado a educação básica é considerada uma etapa da educação importante para a emancipação dos sujeitos, por outro lado, os dados apontam uma precariedade no que diz respeito a sua qualidade. Este é um desafio posto para governos, sociedade civil, agências formadoras e docentes que intencionam uma realidade educativa de qualidade para todos e todas.

Da mesma forma, entendemos e defendemos que as políticas públicas educacionais que almejam uma melhor qualidade da educação necessitam ser subsidiadas em estudos, pesquisa e diagnósticos já existentes, a fim de traçar 
estratégias de intervenção e acompanhamento, implicando na melhoria do nível de escolarização da população, o atendimento de crianças, jovens e adultos nas redes de ensino, garantindo o direito de aprender dos estudantes e que também sejam capazes de modificar os dados dos indicadores educacionais.

\section{Referências}

ALMEIDA, I.; WOLYNEC, E. A produção de indicadores educacionais no Brasil e a comparação internacional. Revista Brasileira de Estudos Pedagógicos, Brasília, v. 79, n. 193, p. 148-160, set./ dez. 1998. Disponível em: http://rbepold. inep.gov.br/index.php/rbep/article/view/1024. Acesso em: 06 set. 2019.

ALVES, Maria Teresa Gonzaga; SOARES, José Francisco. Contexto escolar e indicadores educacionais: condiçóes desiguais para a efetivação de uma política de avaliaçáo educacional. Educação e Pesquisa. São Paulo, v. 39, n. 1, p. 177194, jan./mar. 2013. Disponível em: <http://www.scielo.br/pdf/ep/v39n1/v39n1a12. pdf>. Acessado em: 01 jun. 2018.

BOGDAN, Roberto C.; BIKLEN, Sari Knopp. Investigaçáo qualitativa em educaçáo. Tradução Maria João Alvarez, Sara Bahia dos Santos e Telmo Mourinho Baptista. Porto: Porto Editora, 1994.

BRASIL. Decreto n. 6.094, de 24 de abril de 2007. Dispóe sobre a implementaçáo do plano de Metas Compromisso Todos pela Educaçáo. Brasília: DF, 2007. Disponível em: < http://www.planalto.gov.br/ccivil_03/_ato2007-2010/2007/ decreto/d6094.htm>. Acesso em: 29 de jun. 2018.

BRASIL. Emenda Constitucional n. 95 de 16 de dezembro de 2016. Altera o Ato das Disposiçóes Constitucionais Transitórias, para instituir o Novo Regime Fiscal, e dá outras providências. Brasília: DF, MEC, 2016. Disponível em: < http://legis. senado.leg.br/legislacao/ListaTextoSigen.action?norma=540698\&id=14374770\&id Binario $=15655553 \& \mathrm{mime}=$ application $/ \mathrm{rtf}>$. Acesso em: 01 de ago. 2018 .

BRASIL. Lei n. 13.005 de 25 de junho de 2014. Aprova o Plano Nacional de Educação (PNE) e dá outras providências. Brasília: DF, MEC, 2014. Disponível em: < http:/www.planalto.gov.br/ccivil_03/_ato2011-2014/2014/ lei/113005.htm>. Acesso em: 29 de jun. 2018.

CABRAL NETO, Antônio; SOUZA, Antônio Lisboa Leitão de; QUEIROZ, Maria Aparecida de. Dimensóes da realidade educacional do Rio Grande do Norte. In: CABRAL NETO, Antônio, OLIVEIRA, Dalila Andrade, VIEIRA, Lívia Fraga (Org.) Trabalho Docente: desafios no cotidiano da educaçáo básica- $1^{a}$ ed. Campinas, SP: Mercado de letras, Natal-RN, 2013. 
DUARTE, Natalia de Souza. O impacto da pobreza no Ideb: um estudo multinível. Revista Brasileira de Estudos Pedagógicos, Brasília, v. 94, n. 237, mai./ago. 2013. Disponível em: http://www.scielo.br/pdf/rbeped/v94n237/a02v94n237.pdf. Acesso em: 6 set. 2019.

FERNANDES, R.; NATENZON, P. E. A evolução recente do rendimento das escolas brasileiras: uma reavaliação dos dados do Saeb. Estudos em Avaliaçáo Educacional, São Paulo, n. 28, p. 3-22, jul./dez. 2003. Disponível em: http://www.fcc.org.br/pesquisa/publicacoes/eae/arquivos/986/986.pdf. Acesso em: 6 set. 2019.

FILHO, Raimundo Barbosa; ARAÚJO, Ronaldo Marcos de Lima. Evasão e abandono escolar na educação básica no Brasil: fatores, causas e possíveis consequências. Educaçáo por Escrito, Porto Alegre, v. 8, n.1, p. 35-48, jan./ jul. 2017. Disponível em: http://revistaseletronicas.pucrs.br/ojs/index.php/porescrito/ article/view/24527/15729. Acesso em: 6 set. 2019.

FREITAS, L. C. Eliminação adiada: o ocaso das classes populares no interior da escola e a ocultação da (má) qualidade do ensino. Educaçáo \& Sociedade, Campinas, v. 28, n. 100, p. 965-987, out. 2007. Disponível em: http://www.scielo. br/scielo.php?pid=S0101-73302007000300016\&script=sci_abstract\&tlng=pt. Acesso em: 6 set. 2019.

FUNDO DAS NAÇÓES UNIDAS PARA A CRIANÇA (UNICEF). Panorama da distorção idade-série no Brasil. 2018. Disponível em: https://www.unicef.org/ brazil/media/461/file/Panorama_da_distorcao_idade-serie_no_Brasil.pdf. Acesso em: 6 set. 2019.

INSTITUTO BRASILEIRO DE GEOGRAFIA E ESTATÍSTICA (IBGE). Síntese dos Indicadores Sociais. 2013. Disponível em: < http://biblioteca.ibge. gov.br/index.php/biblioteca-catalogo?view=detalhes\&id=266778>. Acesso em: 29 jun. 2016.

INSTITUTO NACIONAL DE ESTUDOS E PESQUISAS EDUCACIONAIS ANÍSIO TEIXEIRA (Inep). Nota Técnica - Índice de Desenvolvimento da Educaçáo Básica- Ideb. 2017a. Disponível em: <http://download.inep. gov.br/educacao_basica/portal_ideb/o_que_e_o_ideb/Nota_Tecnica_n1_ concepcaoIDEB.pdf >. Acesso em 01 ago. 2018.

INSTITUTO NACIONAL DE ESTUDOS E PESQUISAS EDUCACIONAIS ANÍSIO TEIXEIRA (Inep). Índice de Desenvolvimento da Educação BásicaIdeb. 2017b. Disponível em: <http://sistemasideb.inep.gov.br/resultado >. Acesso em 01 ago. 2018. 
INSTITUTO NACIONAL DE ESTUDOS E PESQUISAS EDUCACIONAIS ANÍSIO TEIXEIRA (Inep). Sinopse Estatística da Educaçáo Básica 2017. 2018. Disponível em: <http://portal.inep.gov.br/basica-censo-escolar-sinopse-sinopse>. Acesso em: 25 jun. 2018.

INSTITUTO NACIONAL DE ESTUDOS E PESQUISAS EDUCACIONAIS ANÍSIO TEIXEIRA (Inep). Taxa de distorçáo idade-série. 2017c. Disponível em: <http://portal.inep.gov.br/indicadores-educacionais>. Acesso em 25 mai. 2018.

INSTITUTO NACIONAL DE ESTUDOS E PESQUISAS EDUCACIONAIS ANÍSIO TEIXEIRA (Inep). Indicadores Educacionais. Taxa de Rendimento. 2016. Disponível em: < http://portal.inep.gov.br/indicadores-educacionais >. Acesso em 01 ago. 2018.

INSTITUTO NACIONAL DE ESTUDOS E PESQUISAS EDUCACIONAIS ANÍSIO TEIXEIRA (Inep). Dicionário de Indicadores Educacionais: Fórmulas de cálculo. Brasília, 2004. Disponível em: http://portal.inep.gov.br/informacaoda-publicacao/-/asset_publisher/6JYIsGMAMkW1/document/id/486420. Acesso em: 06 set. 2019.

INSTITUTO NACIONAL DE ESTUDOS E PESQUISAS EDUCACIONAIS ANÍSIO TEIXEIRA (Inep). Mapa do Analfabetismo no Brasil. Brasília, 2003. Disponível em: http://portal.inep.gov.br/informacao-da-publicacao/-/asset_ publisher/6JYIsGMAMkW1/document/id/485756. Acesso em: 6 set. 2019.

KLEIN, Ruben; FONTANIVE, Nilma. Alguns Indicadores Educacionais de Qualidade no Brasil de Hoje. Sáo Paulo Perspectiva. São Paulo, v. 23, n. 1, p. 1928, jan./jun. 2009. Disponível em: <http://produtos.seade.gov.br/produtos/spp/ v23n01/v23n01_02.pdf>. Acessado em: 25 jun. 2016.

MACHADO, Danielle Carusi; GONZAGA, Gustavo. O Impacto dos fatores familiares sobre a defasagem idade-série de crianças no Brasil. Revista Brasileira de Educação, v. 61, n. 4, 449-476, out./dez. 2007. Disponível em: http://www.scielo. br/pdf/rbe/v61n4/a02v61n4.pdf. Acesso em: 6 set. 2019.

MATOS, Daniel Abud Seabra; RODRIGUES, Erica Castilho. Indicadores educacionais e contexto escolar: uma análise das metas do Ideb. Estudos em Avaliaçáo Educacional, São Paulo, v.27, n. 66, p. 662-688, set./dez. 2016. Disponível em: http:// publicacoes.fcc.org.br/ojs/index.php/eae/article/view/4012/3269. Acesso em: 06 set. 2019.

MINAYO, M. C. S. \& SANCHES, O. Quantitativo-Qualitativo: Oposição ou Complementaridade? Cadernos de Saúde Pública, Rio de Janeiro, v. 9, n. 3, p. 239-262, jul./set. 1993. Disponível em: http://www.scielo.br/pdf/\%0D/csp/v9n3/02. pdf. Acesso em: 05 de set. 2019. 
PESQUISA NACIONAL POR AMOSTRA EM DOMICÍlIO (Pnad). Brasília: DF, 2015. Disponível em: <http://www.ibge.gov.br>. Acesso em 26 mai. 2016.

PINTO, José Marcelino de Rezende, et. al. Um olhar sobre os indicadores de analfabetismo no Brasil. Revista Brasileira de Estudos Pedagógicos, Brasília, v. 81, n. 199, p. 511-524, set./dez. 2000. Disponível em: http://rbepold.inep.gov.br/ index.php/rbep/article/view/971/945. Acesso em: 6 set. 2019.

PORTELLA, Alysson Lorenzon; BUSSMANN, Tanise Brandão; OLIVEIRA, Ana Maria Hermeto de. A relaçáo de fatores individuais, familiares e escolares com a distorçáo idade-série no ensino público brasileiro. Nova economia, vol.27, n.3, p. 477-509, 2017. Disponível em: https://revistas.face.ufmg.br/index.php/novaeconomia/article/ view/3138/2174. Acesso em: 6 set. 2019.

SOARES, Tufi Machado, et. al. Fatores associados ao abandono escolar no ensino médio público em Minas Gerais. Educação e Pesquisa, São Paulo, v. 41, n. 43, p. 757-772, jul./set. 2015. Disponível em: http://www.revistas.usp.br/ep/article/ view/105654/104346. Acesso em: 6 set. 2019.

SOUZA, Alberto de Mello. A Relevância dos Indicadores Educacionais para a Educação Básica: informaçóes e decisóes. Revista Meta: Avaliaçáo, Rio de Janeiro, v. 2, n.5, p. 153-179, mai/ago. 2010. Disponível em: http://revistas.cesgranrio.org. br/index.php/metaavaliacao/article/view/78/93. Acesso em: 06 set. 2019.

SOUZA, Marcelo Medeiros Coelho de. O Analfabetismo no Brasil sob o Enfoque Demográfico. Cadernos de Pesquisa, n. 107, p. 169-186, jul. 1999. Disponível em: http://www.scielo.br/scielo.php?pid=S0100-15741999000200007\&script=sci_ abstract\&tlng=pt. Acesso em: 6 set. 2019.

VITELLI, Ricardo Ferreira; FRISTCH, Rosangela; CORSETTI, Berenice. Indicadores Educacionais na Avaliação da Educação Básica e Possíveis Impactos em Escolas de Ensino Médio no Município de Porto Alegre, Rio Grande do Sul. Revista Brasileira de Educaçáo, Rio de Janeiro, v. 23, p. 1-25, 2018. Disponível em: http://www.scielo.br/pdf/rbedu/v23/1809-449X-rbedu-23-e230065.pdf. Acesso em: 06 set. 2019. 